\title{
Research on the Influence of Corporate Credit Culture on Corporate Financing Constraints --Panel data analysis based on A-share listed companies
}

\author{
Zhiqiang $\mathrm{Liu}^{1, *}, \mathrm{Lu} \mathrm{Zhou}^{1, * *}$ \\ ${ }^{1}$ Yunnan University of Finance and Economics, YNUFE,Kunming, China
}

\begin{abstract}
This paper takes China's A-share listed companies from 2009 to 2019 as a sample, uses the mixed ols model and the two-way fixed effects model to conduct empirical analysis, and finds that when the corporate integrity culture is strong, the financing constraints faced by the company are lower. This conclusion remains robust after considering endogenous issues. This research not only explores ways to alleviate corporate financing constraints from a new perspective, but also has important practical significance for improving corporate governance and promoting the effective allocation of financial market resources.
\end{abstract}

\section{INTRODUCTION}

Financing constraints have always been a difficult problem faced by enterprises in the development process. Especially in recent years, as China's economic restructuring and economic growth have slowed down, corporate financing is facing more severe challenges. At present, China's monetary policy still holds a stable and neutral policy orientation. Beginning in 2016, the central government has made "deleveraging" the top priority for preventing financial risks. From "financial deleveraging" to "entity deleveraging", it undoubtedly makes corporate financing more difficult. Coupled with a large number of P2P platform failure in China since 2019, the problem of financing difficulties facing Chinese companies has become more prominent. In addition, Chinese companies have higher financing costs. "China Social Financing Environment Report" released in 2018 shows that the financing cost of Chinese corporate bank loans and bond issuance is around $6.60 \%$, while the average financing cost of small loan companies is as high as $21.9 \%$. There is no doubt that higher external financing costs will reduce external financing and restrict the development of enterprises. Therefore, in this context, what methods companies should take to ease financing constraints has become a topic of widespread concern in the academic community.

Information asymmetry theory ${ }^{[1]}$ and agency cost theory ${ }^{[2]}$ are the basis for the study of corporate financing constraints and the main reason for the existence of financial constraints. At present, there is a wealth of research on the causes and influencing factors of corporate financing constraints. A large number of empirical studies have found that financial market development, monetary policy and other macro factors will have an impact on corporate financing constraints ${ }^{[3,4]}$ From a micro perspective, corporate characteristics; director characteristics; analyst attention; audit opinions and other factors can also affect corporate financing constraints $^{[5-7]}$. In addition, the formal system will also have an impact on the financing constraints of enterprises $^{[8]}$. Previous literature shows that the theories and empirical studies related to corporate financing constraints are relatively abundant, and the research related to financing constraints mainly focuses on the study of macro policy changes, corporate governance and the impact of formal institutions on financing constraints. However informal institutions, especially the influence of culture on financing constraints are seldom studied. Considering that China's formal system is not perfect, it is not enough to study financing constraints from the perspective of formal systems. It is necessary to consider corporate culture and formal systems to understand corporate financing constraints more comprehensively.

\section{THEORETICAL ANALYSIS AND RESEARCH HYPOTHESIS}

In an imperfect capital market, information asymmetry is an important reason for the existence of corporate financing constraints ${ }^{[9]}$. Based on this, many scholars seek ways to alleviate financing constraints from the perspective of information asymmetry.

\footnotetext{
369276515@qq.com

**1047502072@qq.com
} 
As information intermediaries play an increasingly important role in the capital market, some scholars have studied the role of analysts, auditors, and other important information intermediaries that link capital suppliers and capital demanders on information asymmetry and financing constraints ${ }^{[7,10]}$. For example, with their own professional capabilities, analysts can, on the one hand, discover internal company information at a lower cost, and on the other hand, make it easier for investors to understand through the interpretation of internal information; auditors can use their professional capabilities to identify the quality of information disclosed by companies and prompt companies to disclose true information. And high-quality accounting information can not only reduce information asymmetry, but also promote the effective supervision of investors over the enterprise, thereby reducing the financing cost of the enterprise and alleviating the financing constraint of the enterprise. In addition, in addition to improving the quality of accounting information, companies can also reduce information asymmetry by improving the level of information disclosure and social responsibility, and alleviate the financing constraints that companies face.

Judging from the existing literature, although many scholars seek ways to alleviate financing constraints from the perspective of how to reduce information asymmetry, they seldom pay attention to the role of corporate integrity culture in it. The domestic literature on corporate integrity culture is mainly about the impact of corporate integrity culture on corporate innovation, corporate competitiveness, and corporate internal governance $^{[11-13]}$, and does not consider its impact on financing constraints.

However, the corporate integrity culture, as a spiritual culture with corporate characteristics formed during the production and operation of the enterprise, has a high cohesion and influence. Companies with a culture of integrity as the core of their corporate culture require consistent words and deeds, which can improve the quality of information disclosure and ease the problem of information asymmetry between the company and external investors. First of all, compared to formal systems such as legal systems and economic systems ${ }^{[14]}$, the high ethical standards contained in corporate integrity culture invisibly restrict management's behavioral decisions, inhibit management's motivation for personal gain, and reduce dishonest behavior, which relieves information asymmetry to a certain extent and reduces the financing constraints of enterprises. Secondly, as a value concept shared by most members of the organization, the value of integrity can significantly improve the moral hazard issues of the organization's internal employees such as perfunctory responsibility and management failure, which also alleviates information asymmetry and reduces financing constraints of enterprises. Finally, as a kind of social norm, integrity culture can easily be observed by organization members and even external stakeholders, and the enterprise is always under the supervision of employees and the public, thus restraining the dishonest behavior of the enterprise, alleviating the information asymmetry and reducing the financing constraints of the enterprise.
Therefore, we believe that corporate integrity culture can significantly reduce corporate financing constraints, and proposes the following hypothesis:

Hypothesis: The stronger the corporate integrity culture, the weaker the corporate financing constraints.

\section{ESEARCH DESIGN}

\subsection{Sample selection and data sources}

In this paper, corporate integrity culture data comes from the CNRDS database, and the financial data come from the CSMAR database. The annual data of A-share listed companies from 2009 to 2019 is selected as the initial sample, and the sample is processed as follows: (1) Remove the financial and insurance industry; (2) Exclude ST and *ST stocks; (3) Exclude companies with assetliability ratios greater than $100 \%$; (4) Exclude companies with incomplete data; (5) In order to avoid the influence of outliers on the empirical results, the data is in $1 \%$ and 99\% have been tailed (Winsorize). In addition, we used Stata16.0 software to process, test, and regress the data.

\subsection{Model design and variable description}

In order to test the impact of corporate integrity culture on corporate financing constraints, we design the following regression model:

$$
\mathrm{KZ}_{\mathrm{i}, \mathrm{t}}=\beta_{1} * \text { Abhonest }_{\mathrm{i}, \mathrm{-}-1}+\beta_{2} * \text { Controls }_{\mathrm{i}, \mathrm{t}-1}+\varepsilon_{\mathrm{i}, \mathrm{t}}
$$

The specific variables are described as follows:

\subsubsection{Dependent variable: financing constraint (KZ)}

We use the KZ index to measure the financing constraints faced by enterprises. The KZ index was proposed by Kaplan K Zingales (1997) ${ }^{[9]}$, Jiang Fuxiu et al. (2016) ${ }^{[15]}$ and Pan Yue et al. (2019) ${ }^{[16]}$ all used the KZ index to measure the financing constraints of enterprises in large sample empirical tests. When $\mathrm{KZ}$ index value of a company is higher, it means that its financing constraints are also greater, and vice versa. The equation for calculating the $\mathrm{KZ}$ index is as follows:

$$
\begin{aligned}
& \mathrm{KZ}_{\mathrm{i}, \mathrm{t}}=-9.7433 *\left(\mathrm{CF}_{\mathrm{i}, \mathrm{t}} / \mathrm{TA}_{\mathrm{i}, \mathrm{t}-1}\right)-33.9658 *\left(\mathrm{DIV}_{\mathrm{i}, \mathrm{t}} / \mathrm{TA}_{\mathrm{i}, \mathrm{t}-1}\right)- \\
& \text { 4.3088*(CASH } \left.\mathrm{CH}_{\mathrm{i}, t} / \mathrm{TA}_{\mathrm{i}, \mathrm{t}-1}\right)+5.7117 * \mathrm{LEV}_{\mathrm{i}, \mathrm{t}}+0.3632 * \mathrm{Q}_{\mathrm{i}, \mathrm{t}}
\end{aligned}
$$

Among them, $\mathrm{Cf}_{\mathrm{i}, t} / \mathrm{TA}_{\mathrm{i}, \mathrm{t}-1}$ is the operating net cash flow divided by total assets; $\mathrm{DIV}_{\mathrm{i}, t} / \mathrm{TA}_{\mathrm{i}, \mathrm{t}-1}$ is cash dividends divided by total assets; $\mathrm{CASH}_{\mathrm{i}, t} / \mathrm{TA}_{\mathrm{i}, \mathrm{t}-1}$ is cash holdings divided by total assets, $\mathrm{LEV}_{\mathrm{i}, \mathrm{t}}$ is debt divided by total assets, and $\mathrm{Q}_{\mathrm{i}, \mathrm{t}}$ is Tobin's $\mathrm{Q}$ value.

\subsubsection{Independent variable: corporate integrity culture (Abhonest)}

Drawing lessons from Wang Yan (2014) ${ }^{[17]}$, we use a comprehensive scoring method to measure the level of 
corporate integrity culture, comprehensively measuring from the dimensions of whether the company has been litigated, punished, and condemned, and the quality of company information is disclosure. The specific method is: when a listed company has a new lawsuit and is a defendant, the value is 1 , otherwise it is 0 ; when the company violates regulations, the value is 1 , otherwise it is 0 ; when the company executives are publicly punished or publicly condemned, The value is 1 , otherwise it is 0 ; when the information disclosure quality is excellent/A, the value is 0 , when it is $\operatorname{good} / \mathrm{B}$, the value is 1 , and when it is pass/C, the value is 2 and when it is poor/D, it is The value is 3 . The above four factors is summed up as the company's Abhonest. The smaller the value is, the better the honesty culture will be.

\subsubsection{Control variable}

With reference to Pan Yue (2019) ${ }^{[16]}$, we controls the following variables: Enterprise size (Size), which is the logarithm of total assets; Profitability (Roe), which is return on net assets; Corporate growth (Growth), which is the growth rate of main business income; Asset tangibility (Fixratio), namely tangible assets/total assets; Solvency (Solvency), namely profit before interest and taxes/total liabilities; Risk level (Risk), which is the standard deviation of the company's daily market rate of return for the year. In addition, we also controlled the year and industry effects. Finally, in order to alleviate the impact of endogenous to a certain extent, the independent variable and the control variable are processed with a lag of the dependent variable.

\section{EMPIRICAL RESULT ANALYSIS}

\subsection{Descriptive statistical analysis}

In TABLE I, the descriptive statistical results of the full sample are listed. The minimum value of $\mathrm{KZ}$ is -6.231 , the maximum value is 6.077 , and the median is 1.531 , indicating that the financing constraints of different companies are quite different, and most companies have higher financing constraints. The minimum value of Abhonest is 0 , the maximum value is 6 , and the median value is 1 , indicating that there are differences in the corporate integrity culture, and most companies are relatively honest. Other control variables are shown in TABLE I.

\subsection{Analysis of regression results}

TABLE II shows the regression test results of model (1). Among them, column (1) is a univariate regression, column (2) is a mixed OLS regression, and column (2) is a two-way fixed effects regression. The Abhonest coefficient in column (1) is 0.3297 , which is significant at the $1 \%$ level, indicating that when the corporate integrity culture is strong, the company's financing constraints are lower, which supports the hypothesis; column (2) adds control variables on the basis of column (1), and the Abhonest coefficient is still positive and significant at the $1 \%$ level, which also supports the hypothesis. Column (3) uses a two-way fixed-effects model for regression, and the results show that the Abhonest coefficient is significant at the $5 \%$ level, which further supports the hypothesis. The results are listed in TABLE II (1) - (3) all support that the stronger the corporate integrity culture, the weaker the corporate financing constraints, and the hypothesis in this article is valid.

TABLE I. DESCRIPTIVE STATISTICS

\begin{tabular}{|c|c|c|c|c|c|c|}
\hline Stats & $\mathbf{N}$ & Min & Mean & P50 & Max & Sd \\
\hline $\mathbf{K} \mathbf{z}_{i, t}$ & 19900 & -6.231 & 1.262 & 1.531 & 6.077 & 2.286 \\
\hline $\begin{array}{c}\text { Abhon } \\
\text { est } t_{i, t}\end{array}$ & 19900 & 0.000 & 0.977 & 1.000 & 6.000 & 0.887 \\
\hline Size $_{i, t}$ & 19900 & 14.940 & 22.240 & 22.070 & 28.340 & 1.303 \\
\hline Roe $_{i, t}$ & 19900 & -72.150 & 0.041 & 0.067 & 0.874 & 0.714 \\
\hline $\begin{array}{c}\text { Growt } \\
\mathbf{h}_{\mathrm{h}, \mathrm{t}}\end{array}$ & 19900 & -1.309 & 1.198 & 0.114 & 14900 & 106.500 \\
\hline $\begin{array}{c}\text { Fixrati } \\
\mathbf{o}_{i, \mathrm{t}}\end{array}$ & 19900 & 0.076 & 0.920 & 0.954 & 1.000 & 0.099 \\
\hline $\begin{array}{c}\text { Solven } \\
\text { cy }_{i, t}\end{array}$ & 19900 & -22.390 & 0.198 & 0.115 & 11.800 & 0.464 \\
\hline Risk $_{i, t}$ & 19900 & 0.000 & 0.018 & 0.016 & 0.040 & 0.007 \\
\hline $\mathbf{M s h}_{i, t}$ & 19900 & 0.000 & 0.800 & 1.000 & 1.000 & 0.400 \\
\hline
\end{tabular}

TABLE II. REGRESSION RESULTS OF CORPORATE INTEGRITY CULTURE AND CORPORATE FINANCING CONSTRAINTS

\begin{tabular}{|c|c|c|c|}
\hline & (1) & (2) & (3) \\
\hline \multirow{2}{*}{ Variables } & $\begin{array}{l}\text { Univariate } \\
\text { regression }\end{array}$ & $\begin{array}{l}\text { Mixed ols } \\
\text { regression }\end{array}$ & $\begin{array}{l}\text { Two-way fixed } \\
\text { effects model }\end{array}$ \\
\hline & $\mathbf{K} \mathbf{z}_{\mathrm{i}, \mathrm{t}}$ & $\mathbf{K} \mathbf{z}_{\mathbf{i}, \mathbf{t}}$ & $\mathbf{K} \mathbf{z}_{\mathrm{i}, \mathrm{t}}$ \\
\hline Abhonest $t_{i, t-1}$ & $\begin{array}{c}0.3297 * * * \\
(18.2680)\end{array}$ & $\begin{array}{c}0.2302 * * * \\
(14.5516)\end{array}$ & $\begin{array}{c}0.0395^{* *} \\
(2.1769) \\
\end{array}$ \\
\hline Controls $_{\mathrm{i}, t-1}$ & & $\mathrm{Y}$ & $\mathrm{Y}$ \\
\hline Year & Y & Y & Y \\
\hline Industry & Y & Y & \\
\hline $\mathbf{N}$ & 19,888 & 19,888 & 16,846 \\
\hline $\mathbf{R}^{2}$ & 0.098 & 0.376 & 0.072 \\
\hline
\end{tabular}

Note: ***, $* *$ and $*$ indicate significant at the statistical levels of $1 \%, 5 \%$ and $10 \%$ respectively The data in brackets is the $\mathrm{t}$ value.

\subsection{Endogenous analysis}

The relationship between corporate integrity culture and corporate financing constraints may have endogenous problems caused by missing variables. We use the instrumental variable method to deal with possible endogenous problems.

Since the regional education level (Edu) can significantly affect the local credit level (Tan Yanzhi et al., 2014) ${ }^{[18]}$, we take the regional education level (Edu) as an explanatory variable of the corporate integrity culture (Abhonest) for the first stage of regression and test the relationship between regional education level and financing constraints $(\mathrm{Kz})$. We found that there is a significant correlation between regional education level and corporate integrity culture, but there is no significant relationship with financing constraints. Therefore, we select the regional education level as an instrumental variable, and uses a two-stage regression method to deal with the endogenous problem.

In the first stage, the regional education level was controlled as an instrumental variable. In the second 
stage, after controlling the control variables of model (1), the main text was repeated. Table 3 reports the regression results of the two stages. It can be seen from the first stage that the regional education level and the corporate integrity cultureare significantly negatively correlated, indicating that the higher the regional education level, the stronger the corporate integrity culture. In the second stage, the signs of the main variables are consistent with the previous conclusions, and the corporate integrity culture and financing constraints are significantly negative. The results show that the stronger the corporate integrity culture, the lower the financing constraints faced by the company. So after solving the endogenous problem, the conclusion of this article is still valid, and the research conclusion is robust.

Therefore, the results after solving the endogenous problem can support the hypothesis and research conclusion of this article.

TABLE III. ENDOGENOUS TEST RESULTS

\begin{tabular}{|c|c|c|}
\hline & $(\mathbf{1})$ & (2) \\
\hline \multirow{2}{*}{ Variables } & The first stage & The second stage \\
\cline { 2 - 3 } & Abhonest $\mathrm{t}_{\mathrm{i},-1}$ & $\mathbf{K z}_{\mathrm{i}, \mathrm{t}}$ \\
\hline \multirow{2}{*}{ Abhonest } & & $0.404^{*},-1$ \\
& & $(1.71)$ \\
\hline Edu $_{i,-1}$ & $-0.000^{* * *}$ & \\
\hline Controls $_{\mathrm{i},-1}$ & $(-9.89)$ & $\mathrm{Y}$ \\
\hline Year & $\mathrm{Y}$ & $\mathrm{Y}$ \\
\hline Industry & $\mathrm{Y}$ & $\mathrm{Y}$ \\
\hline $\mathbf{N}$ & 19,815 & 19,815 \\
\hline $\mathbf{R}^{2}$ & 0.156 & 0.351 \\
\hline
\end{tabular}

Note: ***,** and * indicate significant at the statistical levels of $1 \%, 5 \%$ and $10 \%$ respectively; The data in brackets is the $\mathrm{t}$ value.

\section{CONCLUSION AND INSPIRATION}

We take listed A-share companies of China as a sample from 2009 to 2019, and examines whether corporate integrity culture affects corporate financing constraints from an informal institutional perspective. We find that a strong corporate integrity culture can help ease the financing constraints of companies. The conclusions of this paper are still robust after solving possible endogenous problems.

Based on the above conclusions, we can draw the following conclusions: (1) From the perspective of country, great importance should be attached to the role of informal institutions. The good complementarity of corporate integrity culture and formal systems will help to effectively allocate financial market resources and promote the sustained and healthy development of the Chinese economy.(2) From the perspective of enterprises, they should strengthen the construction of the company's integrity culture, and improve the company's financing capabilities by formulating a reasonable corporate culture.

\section{ACKNOWLEDGMENT}

This work was supported by the National Natural Science Foundation of China [grant numbers 71162003, 71662035] and the Scientific Research Fund Project of Yunnan Education Department [grant numbers 2021Y536].

\section{REFERENCES}

1. Stiglitz, Joseph E., and Andrew Weiss. "Credit Rationing in Markets with Imperfect Information." The American Economic Review, 1981, vol. 71, pp. $740-741$

2. Jensen, Michael C., and William H. Meckling. "Theory of the Firm: Managerial Behavior, Agency Costs and Ownership Structure." SSRN Electronic Journal, 1976, vol. 3, pp. 360

3. Xie, Jun, and Zhizhong Huang. "Macro Monetary Policy, Regional Financial Development and Corporate Financing Constraints--Micro Evidence of Monetary Policy Transmission Mechanism." Accounting Research, 2013, pp. 63-69.

4. Yao, Yaojun, and Gangfeng Dong. "Mitigation of SME financing constraints: whether the level of financial development is important or the financial structure is important?--Empirical evidence from listed companies on the SME board." Financial Research, 2015, pp. 148-61.

5. Hadlock, Charles J., and Joshua R. Pierce. "New Evidence on Measuring Financial Constraints: Moving Beyond the KZ Index." Review of Financial Studies, 2010, vol. 23, pp. 1909-1940.

6. Krishnan, et al. "Legal Expertise on Corporate Audit Committees and Financial Reporting Quality." Accounting Review, 2011, pp. 2099-2130.

7. Gu, Fenling, and Jiaoyang Xie. "Internal Control Defects, Auditor's Opinions and Corporate Financing Constraints--Based on the Empirical Data of China's A-Share Main Board Listed Companies." Accounting Research, 2018, pp. 77-84.

8. Shen, Xianghua. "An Empirical Test of Government Subsidies, Property Rights and Debt Financing Effects." Economic Jingwei, 2015, vol. 32, pp. 13843.

9. Kaplan, Steven N., and Luigi Zingales. "Do Investment-Cash Flow Sensitivities Provide Useful Measures of Financing Constraints?" Quarterly Journal of Economics, 1997, vol. 112, pp. 169-215.

10. Fan, Yunrui, and Chenying Li. "Analyst Attention, Internal Control and Corporate Debt Financing Constraints." Finance and economy, 2019, pp. 2530 .

11. Xie, Fenghua, and Gongmin Bao. "Research on the relationship between corporate integrity and competitive advantage_-Based on an empirical survey of 188 companies in six places including Suzhou." Nankai Management Review, 2005, pp. 21-22.

12. Jiang, Fuxiu, Beibei Shi, and Xingtian Li. "Is "Honesty" an Enterprise Honesty?_-Based on 
Empirical Evidence from Earnings Management." Accounting Research, 2015, pp. 24-31.

13. Tang, Wei, Wenjing Cai, and Yeguang Cui. ""Integrity" Culture and Enterprise Innovation." Scientific Research Management, 2020, vol. 41, pp. 11-22.

14. Putnam, Robert D. "What Makes Democracy Work?" National Civic Review, 1993, vol. 82, pp. 101-07.

15. Jiang, Fuxiu, Beibei Shi, and Ma Yunbiao. "Information publisher's financial experience and corporate financing constraints." Economic Research, 2016, vol. 51, pp. 83-97.

16. Pan, Yue, Bo Ning, and Xiangge Ji. "The clan brand of private capital: evidence from the perspective of financing constraints." Economic Research, 2019, vol. 54, pp. 94-110.

17. Wang, Yan. ""Integrity and Innovation Values" Cultural Difference and M\&A Performance--Based on the Empirical Data of Shanghai and Shenzhen Listed Companies' Equity M\&A Events from 2008 to 2010." Accounting Research, 2014, pp. 74-80.

18. Tan, Yanzhi, Wang Chao, and Guofeng Li. "The Economic Performance of the Credit Environment and its Influencing Factors-Based On the CEI Index and Data From China's Provincial and PrefectureLevel Cities." Economic Survey, 2014, vol. 31, pp. 144-49. 